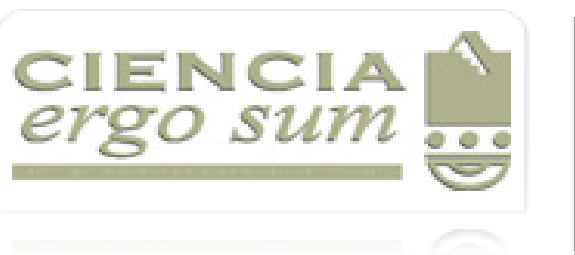

Ciencia Ergo Sum

ISSN: 1405-0269

ciencia.ergosum@yahoo.com.mx

Universidad Autónoma del Estado de México México

León, David de; Manjarrez, Lorena; Ang, Alfredo H-S.

Structural Reliability of the Tampico Bridge under Wind Loading

Ciencia Ergo Sum, vol. 15, núm. 2, julio-octubre, 2008, pp. 161-166

Universidad Autónoma del Estado de México

Toluca, México

Available in: http://www.redalyc.org/articulo.oa?id=10415207

How to cite

Complete issue

- More information about this article

Journal's homepage in redalyc.org

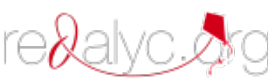

Scientific Information System Network of Scientific Journals from Latin America, the Caribbean, Spain and Portugal Non-profit academic project, developed under the open access initiative 


\title{
Structural Reliability of the Tampico Bridge under Wind Loading
}

\author{
David de León*, Lorena Manjarrez* y Alfredo H-S. Ang**
}

Recepción: 25 de septiembre de 2007

Aceptación: 3 de abril de 2008

*Facultad de Ingeniería, Universidad Autónoma del Estado de México, México.

Correo electrónico: david_deleon0585@yahoo.com.mx **School of Engineering, University of California at Irvine.

We thank the Communications and Transportation Secretary in Mexico for the information provided about the Tampico bridge.
Confiabilidad estructural del Puente de Tampico bajo cargas de viento

Resumen. Se analiza un puente carretero localizado en Tampico, en la costa este de México, para determinar su confiabilidad estructural ante cargas de viento. Las variabilidades inherentes a las fuerzas aleatorias de viento y a las propiedades mecánicas del acero constituyen las incertidumbres aleatorias, y esto contribuye a la probabilidad de falla de las vigas de acero. La idealización de la carga y la estructura del puente, así como el análisis de la respuesta estructural ante la carga de viento, contribuyen a que exista una incertidumbre adicional, de tipo epistémico, que deriva en un rango (o distribución) de posibles probabilidades de falla. El diseño con el mínimo del costo esperado en el ciclo de vida se asocia con el diseño óptimo. Sin embargo, para este diseño óptimo, es posible seleccionar el percentil 90, por ejemplo, (o la media más una desviación estándar) de la probabilidad de falla o índice de confiabilidad correspondiente, para administradores con aversión al riesgo, lo cual constituye una decisión conservadora. El criterio propuesto constituye una nueva aproximación para tomar decisiones conservadoras e involucrar a la incertidumbre epistémica en el proceso de diseño y evaluación de puentes.

Palabras clave: confiabilidad de puentes, costo esperado en el ciclo de vida, diseño óptimo, cargas de viento, incertidumbre epistémico

\begin{abstract}
A highway bridge located in Tampico, on the east coast of Mexico, is analyzed to determine its structural reliability against wind loading. The inherent variabilities of the random wind force and of the mechanical properties of steel constitute the aleatory uncertainty; this contributes to the probability of failure of the steel girder. The idealization of the loading and of the bridge structure, and the analysis of the structural response to wind loading, contribute to additional uncertainty of the epistemic type, which leads to a range of possible (or distribution of) failure probabilities. The design with the minimum expected life-cycle cost is the optimal design. However, for this optimal design, the $90 \%$ value (or the mean plus one standard deviation value) of the corresponding failure probability or safety index may be selected for a risk-aversive design. The proposed criteria constitute a new approach to make conservative decisions and involve the epistemic uncertainty on the bridge design and assessment process.

Key words: bridge reliability, expected life-cycle cost, optimal design, wind loading, epistemic uncertainty.
\end{abstract}

\section{The Tampico bridge}

Bridges are important infrastructure because of its intended function to provide communication between urban centers and to allow the flow of products and goods that determine the progress of economic and industrial growth of a region.
In particular, the Tampico bridge, which was built over the Pánuco river in 1988 serves as a link between the Tamaulipas and Veracruz states and joins Tampico to the highway to Mexico City.

The bridge structural system is composed by a cable stayed steel orthotropic box sustained by concrete piers and 
piles with a total length of $1543 \mathrm{~m}$ and a central span of 360 $\mathrm{m}$. The total width is $18.10 \mathrm{~m}$ for four lanes of traffic, two in each direction. See Fig. 1 for a view of the bridge.

A new risk-based approach is proposed to assess the failure consequences and incorporate them into the design or evaluation process in an objective and explicit way.

\section{Theoretical background}

Modern codes intend to protect important infrastructure works against strong and unpredictable natural events (AASHтO, 2002 and Agarwal, 2003). In addition to the vehicle live loads, bridges are exposed to strong winds whenever they are located on coastal zones under strong wind hazard. Besides, because of its height and the openness of the area the exposure may be especially critical. Therefore, in these cases the bridge reliability assessment requires a careful consideration of the failure probability associated with the aleatory uncertainty, and the range (or error bound) in the calculated probability as a result of the epistemic uncertainty (Ang and De León, 1997; 2005 and Ang et al., 1984).

The effects of the uncertainties on the bridge design and maintenance are discussed from the standpoint of the expected life-cycle costs and its expected failure probability (De León et al., 2004; Frangopol et al., 2007 a and 2007b). As a consequence of the epistemic uncertainty the mean damage index becomes a random variable and, given that the failure probability and the expected life-cycle cost depend on the damage index, they also are random variables.

As proposed for many important structures (Ang et al., 1984; Cornell, 1969 and Stahl, 1986), the bridge expected

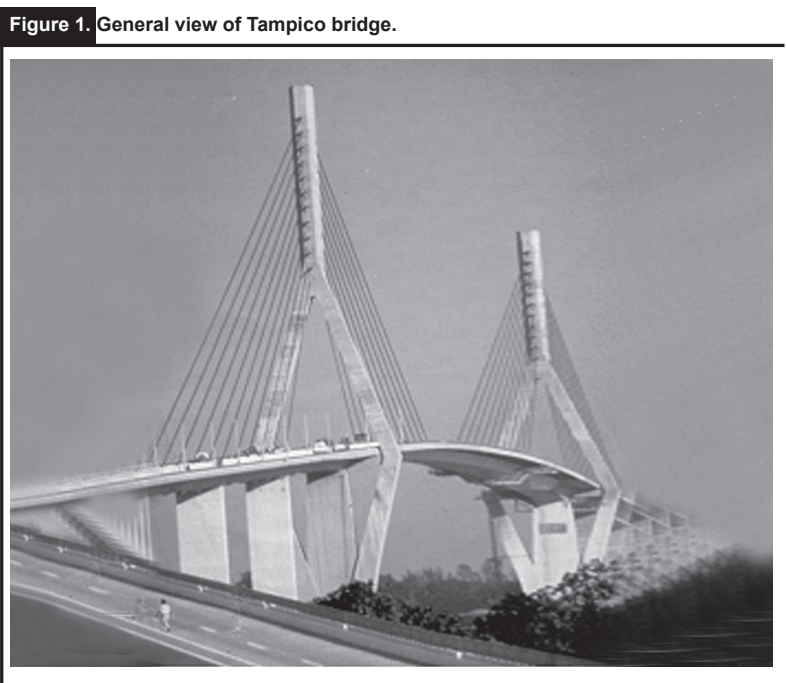

life-cycle cost $\mathrm{E}[\mathrm{Ct}]$ is expressed in terms of the initial cost $\mathrm{Ci}$ and the expected damage cost $\mathrm{E}[\mathrm{Cd}]$

$E\left[C_{t}\right]=C_{i}+E\left[C_{d}\right]$

where:

$E\left[C_{d}\right]=P V F\left[C_{d}\right] P_{f}$

in which:

$P V F=$ present value factor, $P_{f}=$ annual failure probability, and the damage cost $C_{d}$ is composed by the costs of the consequences.

$C_{d}=C_{r}+C_{f}+C_{e}$

in which:

$C_{r}=$ bridge restitution cost,

$C_{f}=$ cost related to fatalities and injuries,

$C_{e}=$ economic loss due to the interruption of service.

The assessment considers the failure event as the worst possible scenario. Instead of repair, the term $\mathrm{C}_{r}$ involves the cost of the whole bridge restitution.

$P V F$ is expressed as a function of the net annual discount rate $\mathrm{r}$ and the structure life $T$ :

$P V F=[1-\exp (-r T)] / r$

If the initial cost $C_{i}$ is expressed in terms of the failure probability

$C_{i}=C_{1}-C_{2} \ln \left(P_{f}\right)$

the optimal failure probability is obtained (Stahl, 1986) from $\partial E\left[C_{t}\right] / \partial P_{f}=0$ :

$P_{f}=C_{2} /\left[P V F\left(C_{d}\right)\right]$

From the optimal annual $P_{f}$, the optimal annual reliability index $\beta$ is obtained.

$C_{1}$ and $C_{2}$ are the cost due to just a gravity loading design, without wind resistance, and the cost of increasing the structural reliability by " $\mathrm{e}$ ", the base of natural Logarithms.

As several designs, with corresponding different costs $C_{i}$, will be proposed, a reference is made to the actual design, whose cost is $C_{o}$.

The cost of damage consequence, $C_{d}$, is expressed (De León, 2006) as a ratio to the cost of the actual design $C$. Given that the Tampico bridge is located over the Panuco River, the 
only navigation route to the port, its failure would bring very adverse consequences not just for the land communication but for the port and maritime commercial operations of the region. Therefore, $C_{d}$ has been estimated to be thousands of time the actual design cost $C_{0}$ (Manjarrez, 2008) (see figure. 2).

The curve represents that expensive structures, with serious damage consequences, demand a larger reliability as a design requirement. In particular, bridges are important infrastructure whose damage consequences justify a reliability specification on the order of 4 or 5 .

\section{Proposed formulation}

\subsection{Uncertainty on failure probability and \\ life-cycle cost}

According to previous studies (De León et al., 2004), and given that the epistemic uncertainty on the mean value of maximum wind velocity, $E[v]$, makes the failure probability become a random variable, the expected value and variance of the failure probability are:

$E\left[P_{f}\right]=\int_{0}^{\infty}\left[P_{f}: E[v]\right] f_{E[v]}(E[v]) d E[v]$

The above convolution involves the product of the conditional failure probability for given values of the expected maximum wind velocity $v$ and $f_{E[V]}(E[v])$, the annual $p d f$ of the mean value of maximum wind velocity.

$\sigma^{2} P_{f}=\int_{0}^{\infty}\left\{P_{f}-E\left[P_{f}\right]\right\}^{2} f_{V}(v) d v$

It is assumed that $E[v]$ is normal and its COV has been found to be 0.2 from previous studies (De León, 2006b).

Similarly

$E\left\{E\left[C_{t}\right]\right\}=C_{i}+E\left\{E\left[C_{d}\right]\right\}$

and:

$$
\begin{aligned}
\sigma_{E\left[C_{t}\right]}^{2}= & \left(C_{i} \Delta C_{i}\right)^{2}+\sigma_{E\left(C_{r}\right)}^{2}+ \\
& \sigma_{E\left(C_{f}\right)}^{2}+\sigma^{2}{ }_{E\left(C_{e}\right)}
\end{aligned}
$$

where $C_{i}$ is normal and $\Delta C_{i}$ is the $\mathrm{COV}$ (coefficient of variation) of $C_{i}$, which may be assumed to be 0.10 and $\sigma^{2} E\left(C_{r}\right)$, $\sigma^{2} E\left(C_{f}\right)$ and $\sigma^{2} E\left(C_{e}\right)$ are the variances of the mean values of the economic consequences: repair, fatalities and business interruption which are also assumed to be normally distributed. These assumptions are typical from previous studies (De León, 2006a and Manjarrez, 2008).

The reliability index is calculated as

$\beta=E\{G\} / \sigma_{G}$

where $G$ is the limit state for the critical cross section:

$G=1-\left\{P_{a} / P_{r}+M_{a} / M_{r}\right\}$

And $P_{a}, P_{r}, M_{a}$ and $M_{r}$ are the applied axial force, axial force capacity, applied moment and moment capacity, respectively in the most critical column. Failure is conservatively defined as the event when the interaction ratio in the most critical column exceeds one. Shear forces are not included because the preliminary model analyses revealed they are not critical for the studied bridge. The preliminary analyses enlighten that the critical structural member is one of the central piles remarking the low redundancy of the bridge structural system and, therefore, the need of more detailed assessment and design procedures.

Finally, the histograms of the failure probability and the expected life-cycle cost are estimated. Also, the 90 and 75 percentiles of these variables are calculated as examples of conservative confidence levels, as opposite to the traditional use of the mean value.

In equation (3), the damage cost $C_{d}$ is composed of the cost components $C_{r}, C_{f}$ and $C e$ each of which also has epistemic

Table 1. Cost components and epistemic uncertainties.

\begin{tabular}{ll}
\hline Cost component & COV \\
\hline $\mathrm{C}_{r}$ (restitution) & 0.2 \\
$\mathrm{C}_{e}$ (Economic loss) & 0.4 \\
$\mathrm{C}_{f}$ (Life loss) & 0.8 \\
\hline
\end{tabular}


uncertainty, as described in table 1, with values obtained from previous works (De León, 2006b and Manjarrez, 2008).

Given that the life loss is a very uncertain parameter, which depends on the bridge failure and the bridge occupancy at the time of failure, and there is very scarce data to characterize it, it is assumed its variability is the double of the one for the economic loss. Further research should result on a more accurate estimation of this parameter.

A double loop Monte Carlo simulation is performed to vary the expected value of maximum wind velocity and, in the inner loop, the maximum wind velocity. The simulation considers the extreme type distribution found to be the best fit for the strong winds of Tampico and the epistemic uncertainty on the estimation of the mean maximum wind velocity.

\section{Application to Tampico bridge}

\subsection{Estimation of Cost Items}

The cost of damage consequence, $C_{d}$, is estimated to be 2000 $C_{o}$ (Manjarrez, 2008) and from previous results (Ang and De León, 2005; De León, 2006a and 2006b):

$C_{2}=0.045 C_{i}$, for a typical cable-stayed bridge

$r=0.08$, for Mexico

$T=200$ years
The optimal failure probability from Eq. (6) does not consider the epistemic uncertainty. In the following, epistemic uncertainty is included to account for the incomplete knowledge on the wind velocity model, as well as on the response analysis. Therefore, the procedure above described is developed for the Tampico bridge.

The bridge is modeled and its response is obtained for several basic wind velocities and the original design is modified by reducing or increasing all cross sections according to the design requirements. Through this process, a set of alternative designs is obtained and their corresponding costs are estimated for typical local costs in the city of Tampico. This set serves to identify the specific design whose failure probability is closest to the optimal one. The following material properties were utilized: $\mathrm{f}^{\prime} \mathrm{c}=250 \mathrm{Kg} / \mathrm{cm} 2$ and fy $=4200 \mathrm{Kg} / \mathrm{cm} 2$. The resulting curve for the set of alternative designs, whose costs $C_{i}$ are relative to the cost $C_{o}$ of the actual design is shown in figure 3 .

It is observed that, for the actual design, the reliability index of 4.72 is slightly below the optimal value of 4.8 for the case of $C_{d}=2000 C_{o}$. In this case none can say the bridge is at significant risk, however the risk perception is important for the manager and users (Renn, 1998) and, for important infrastructures like the Tampico bridge is essential to count with a procedure that allows the managers or operators to tailor their own maintenance program according to their risk aversion or perception.

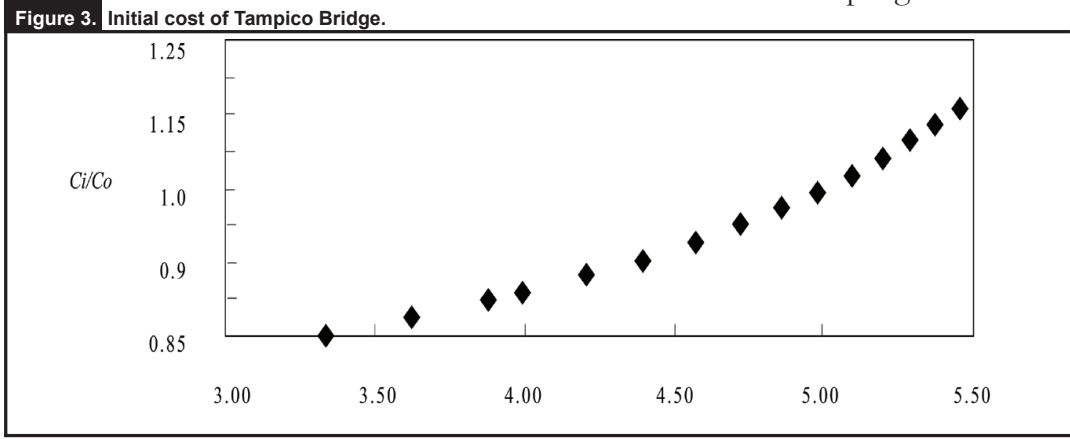

Figure 4. Maximum annual wind velocities at Tampico.

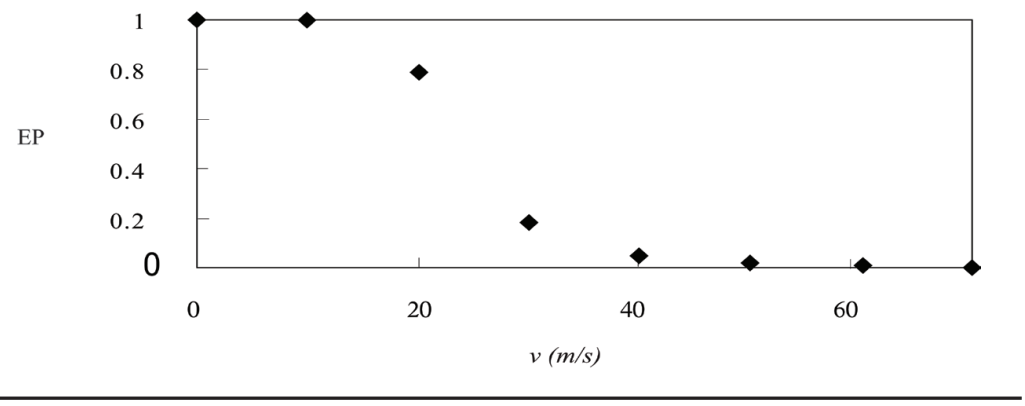

In this way, conservative decisions may be devised and implemented to keep the bridge within safe operating conditions.

\subsection{Uncertainty on wind velocity}

Wind velocities on coastal zones need to be probabilistically modeled (Sánchez-Sesma et al., 1998). From a previous statistical analysis (Sánchez, 2003) a Type II extreme value distribution was found to be the best fit to the maximum annual wind velocities based on past hurricanes recorded in the east cost of Mexico. The distribution is:

$F_{V}(v)=\exp \left[-(21.82 / v)^{5}\right]$

And the annual exceedance probability, $\mathrm{EP}$ is shown in figure 4. 


\subsection{Calculation of optimal failure probability and life-cycle cost}

With the wind velocity distribution shown in Eq. (23), and, assuming a COV of 0.2 (Manjarrez, 2008 and Sánchez, 2003) for the epistemic uncertainty in the estimation of the mean wind velocity, and the assumption that the mean wind has a lognormal distribution, a number of wind velocities were simulated. From these simulated velocities, the wind forces, dead load and live load effects were calculated for the optimal bridge design and the bridge responses were also obtained. From these responses, the limit state $G$ was assessed and the distribution of the optimal reliability index was calculated. A sample of the calculations is shown in tables 2 and 3 . The cross section of a critical pile is a box of $240 \times 640 \mathrm{~cm}$ dimensions and $50 \mathrm{~mm}$ thickness.

A histogram of the optimal expected reliability index is constructed. Similarly, the histogram for the optimal expected cost is obtained relative to the actual design cost. See figures 5 and 6 . Tables 4 and 5 show the mean values, the 75 and 90 percentile values for both results; i.e., for the optimal reliability and optimal life-cycle cost.

\section{Discussion}

Histograms of the optimal failure probability and expected life-cycle costs allow for conservative decisions. That is, instead of selecting the mean values, either the 75 or the 90 percentile value may be selected. By doing this, the epistemic uncertainty on the prediction model for the main design parameter, the wind velocity, is incorporated and taken into account in the design selection process. Recent changes on the meteorological and hurricane parameters and patterns, with stronger effects on urban and industrial developments on the shoreline, is becoming a concern for safety requirements and mitigation measures, specially for infrastructure located on the coast and exposed to very intense wind. Under these conditions, a more detailed assessment of the impact of the epistemic uncertainties on the load prediction and response models, such as the one formulated and applied here, appears to be justified. Authorities in charge of coastal development planning and industry managers may use the above

Table 2. Sample calculations of the reliability index for the optimal design
\begin{tabular}{|ccccccc} 
(Rn = random number). \\
\hline $\mathrm{Rn}$ & $\mathrm{V}(\mathrm{km} / \mathrm{h})$ & $\mathrm{P}_{\mathrm{act}}($ ton $)$ & $\mathrm{M}$ act (ton-m) & $\mathrm{E}[\mathrm{G}]$ & $\sigma \mathrm{G}$ & $\beta$ \\
\hline 0.3156 & 80.82 & 25711 & 30.11 & 0.007 & 0.00259 & 3.52 \\
0.4703 & 74.24 & 25710 & 27.94 & 0.008 & 0.00238 & 3.83 \\
0.6415 & 66.77 & 25709 & 25.66 & 0.008 & 0.00214 & 4.33 \\
0.4198 & 76.35 & 25710 & 28.62 & 0.007 & 0.00245 & 3.72 \\
0.2747 & 82.68 & 25711 & 30.76 & 0.007 & 0.00265 & 3.46 \\
0.4156 & 76.53 & 25710 & 28.68 & 0.007 & 0.00245 & 3.71 \\
0.7281 & 62.43 & 25709 & 24.42 & 0.008 & 0.00200 & 4.02 \\
0.3500 & 79.31 & 25710 & 29.60 & 0.007 & 0.00254 & 3.58 \\
0.9539 & 42.64 & 25707 & 19.49 & 0.009 & 0.00137 & 6.40 \\
0.5679 & 70.09 & 25709 & 26.65 & 0.008 & 0.00225 & 4.08 \\
0.2579 & 83.47 & 25711 & 31.04 & 0.007 & 0.00268 & 3.43 \\
0.4286 & 75.98 & 25710 & 28.50 & 0.007 & 0.00244 & 3.73 \\
\hline
\end{tabular}

Table 3. Critical member resistances for the calculation of the reliability index.

\begin{tabular}{cc}
$\mathrm{P}_{\mathrm{R}}$ (ton) & $\mathrm{M}_{\mathrm{R}}$ Transv. (tn-m) \\
27000 & 8400 \\
\hline
\end{tabular}

Table 4. Mean and acceptable value, and the $\mathbf{9 0}$ and $\mathbf{7 5}$ percentile values of optimal
\begin{tabular}{|cc}
\hline reliability. \\
\hline Mean & 4.17 \\
$90 \%$ & 5.25 \\
$75 \%$ & 4.42 \\
Acceptable & 4.80 \\
\hline
\end{tabular}

\begin{tabular}{|cc}
\hline Table 5. Mean value and the $\mathbf{9 0}$ and $\mathbf{7 5}$ percentile values of optimal cost. \\
\hline Mean & 1995 \\
\hline $90 \%$ & 3900 \\
$75 \%$ & 2500 \\
\hline
\end{tabular}

Figure 5. Histogram of optimal annual $\beta$ index for Tampico bridge.

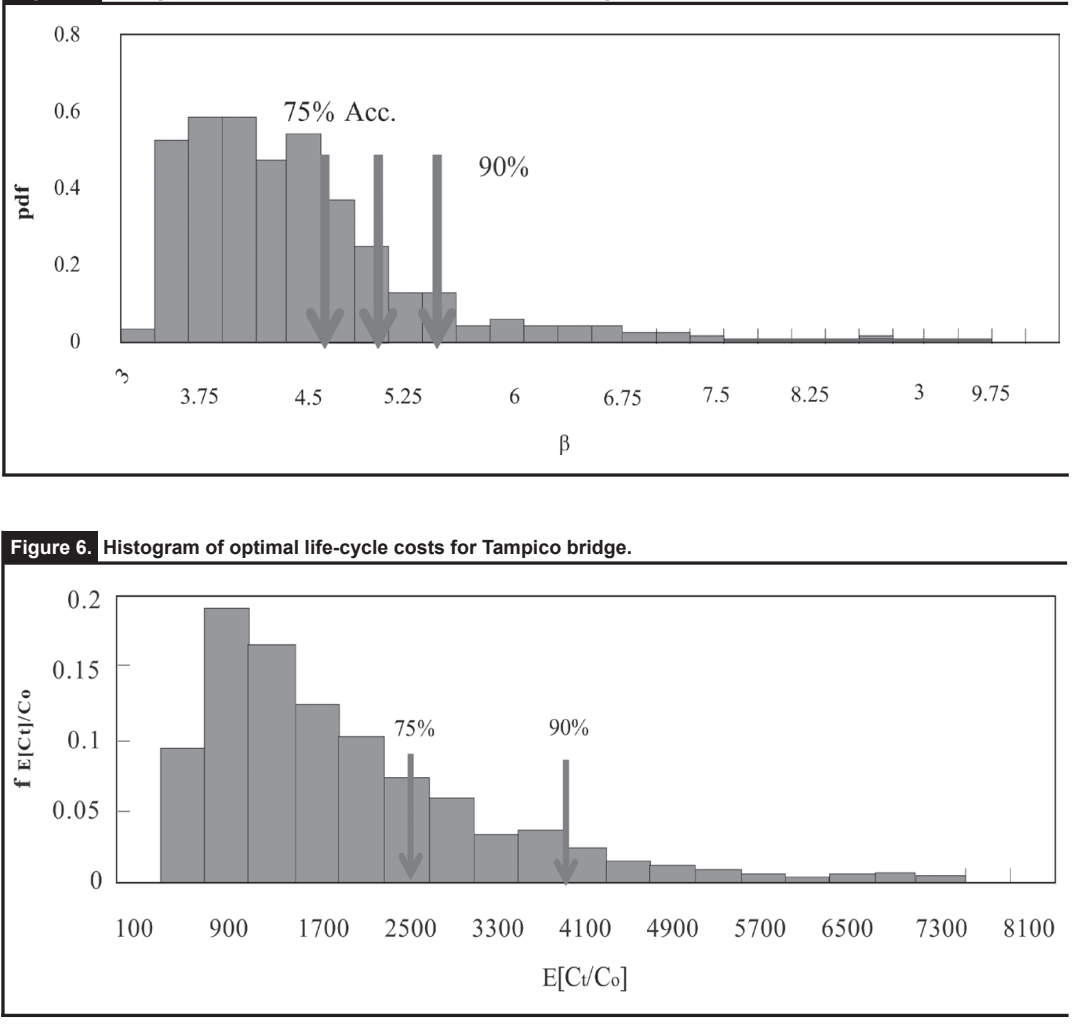


mentioned results for conservative decision making depending on their risk-averseness.

\section{Conclusions and recommendations}

A new structural reliability assessment procedure for bridges has been proposed including the epistemic uncertainty and it has been applied to the Tampico bridge. The random features of the wind speed in the region and the optimal failure probability has been incorporated. The actual design (with $\beta$ $=4.72$ ) is close to the optimal value of $\beta=4.8$.
Aleatory and epistemic uncertainties have been included to describe the variability of the optimal reliability index and its corresponding expected life-cycle cost.

Fatigue and vibration limit states may also be addressed through a formulation similar to the one presented here. The proposed procedure may be further extended to set optimal retrofit plans and inspection and maintenance schedules. Also, the treatment may be applied to other important infrastructure facilities exposed to high speed winds in order to derive safety policies for coastal regions based on risk assessment and management.
AASHTO (2002). Standard Specifications for

Highway Bridges. American Association

of State Highway and Transportation

Officials, us.

Agarwal, J. (2003). "Protecting Existing Structures Against Unforeseen Events", Aplications of Statistics and Probability in Civil Engineering, Der Kiureghian, Madana \& Pestana (EDS.), Millpres, Netherlands, pp. 775-780. Ang, A. H-S.

and D. De León (1997). "Determina-

tion of Optimal Reliabilities for Design and Upgrading of Structures", Structural Safety, Vol. 19, 1, pp. 91-103.

De León, D. (2005). “Modeling and

Analysis of Uncertainties for Risk-informed Decisions in Infrastructures engineering", Journal of Structure and Infrastructure Engineering, Vol. 1, 1, pp. 19-31. and Tang, Wilson H. (1984). Probability Concepts in Engineering Planning and Design. Vol. II - Risk, Reliability and Decisions, John Wiley and Sons, New York.

Cornell, Allin (1969). "A probability-based structural code", ACI Journal, Title No. 66-85.
De León, D.

; A. H. S. Ang and D. Campos (2004). Effects of Uncertainties on the Reliability of a Bridge Connecting two offshore Platforms. Second International Conference on Bridge Maintenance, Safety and Management (IABMAS ’04). Kyoto, Japan.

(2006). "Structural Reliability of the Tampico Bridge under Wind Loading", Procs. IABMAS '06. Oporto, Portugal. Rotterdam: Balkema.

(2006). "Confiabilidad estructural y medidas de riesgo del puente Tampico bajo cargas de viento", Procs. XV National Congress in Structural Engineering, P. Vallarta, Jal., Méx.

Frangopol, D.M.; K. Maute and M. Liu (2007a). "Design Optimization with Uncertainty, Life-cycle Performance and Cost Considerations", Chapter 11 in Optimization of Structural and Mechanical Systems, J. S. Arora, ed., World Scientific Publishing Co.Ptc. Ltd., 291-329.

(2007b). "Maintenance and Management of Civil Infrastructure Based on Con- dition, Safety, Optimization, and Lifecycle Cost", Structure and Infrastructure Engineering, Taylor \& Francis, 3(1), 29-41.

Manjarrez, L. (2008). “Análisis de confiabilidad y costos del puente Tampico", Master Thesis, ESIA, IPN, Méx., DF.

Renn, O. (1998). “The Role of Risk Perception for Risk Management", Reliability Engineering \& System Safety, Vol. 59, No. 1, pp. 49-62

Sánchez, C. O. (2003) "Regionalización eólica para el Estado de Tamaulipas y aplicaciones prácticas en el diseño Estructural de un edificio para la Ciudad de Tampico, Tamaulipas", Thesis for Civil Engineering. Unidad Académica Multidisciplinaria Zona Sur, CUTM, UAT.

Sánchez-Sesma J.; J. Aguirre and Sen Mir (1988). "A Probabilistic Study of Maximum Cyclonic Wind Speeds", J. of the Structural Division, ASCE, Vol. 114, 2.

B. Stahl, (1986). "Reliability Engineering and Risk Analysis", in B. Mc Clelland and M.D. Reifel (editors). Planning and Design of Fixed Offshore Platforms. Chapter 5 from. Van Nostrand Reinhold Co. New York. 